\title{
Retrospective survey for sialidase activity in Mycoplasma pneumoniae isolates from cases of community-acquired pneumonia
}

\author{
Meghan May ${ }^{1 \dagger}$ and Daniel R Brown ${ }^{2^{*}+}$
}

\begin{abstract}
Background: Sialidase is a well-known virulence factor of other respiratory pathogens, but was only recently documented to occur in some species of Mycoplasma. The sialidase activity expressed can vary quantitatively among strains within a species of mycoplasma, from undetectable to amounts that correlate positively with strain virulence. Very few isolates of Mycoplasma pneumoniae had ever been examined for sialidase activity, so it was unknown whether sialidase may contribute to diseases involving this species.

Findings: No sialidase activity was detected by spectrofluorometric assay of 15 laboratory strains and 91 clinical isolates of M. pneumoniae banked over many years from patients having radiologically-confirmed, uncomplicated community-acquired pneumonia.

Conclusions: The annotated genome of strain M129 (GenBank NC_000912, ATCC 29342), also isolated from a patient with pneumonia, accurately represents the absence of sialidase genes from strains of M. pneumoniae typically associated with uncomplicated community-acquired pneumonia. A possible involvement of sialidase in neurologic or other extra-respiratory manifestations of $M$. pneumoniae mycoplasmosis remains to be investigated.
\end{abstract}

\section{Findings}

\section{Research objective}

Mycoplasma pneumoniae is primarily associated with interstitial pneumonitis, tracheobronchitis, desquamative bronchitis and pharyngitis, collectively referred to as primary atypical pneumonia (PAP) [1,2]. Mycoplasmosis accounts for 20 - 30\% of community-acquired pneumonia (CAP) cases, constituting significant disease and economic burdens in North America and Western Europe. Following its initial association with PAP, other diseases involving $M$. pneumoniae invasion of non-respiratory tissues were reported [Table 1]. Neurologic, dermal, hemotropic, cardiac, arthritic, hepatic, pancreatic, nephritic, and musculoskeletal pathologies have been described[2-12]; many of those diseases occurred secondarily to PAP, either through dissemination of M. pneumoniae from the respiratory tract, or following

\footnotetext{
* Correspondence: drbrown@ufl.edu

+ Contributed equally

${ }^{2}$ Department of Infectious Diseases and Pathology, College of Veterinary

Medicine, University of Florida, Gainesville FL, USA

Full list of author information is available at the end of the article
}

associated autoimmune disorders [3]. Primary extrarespiratory $M$. pneumoniae infections in the absence of PAP, including meningoencephalitis, hepatitis, and pancreatitis, have also been described $[13,14]$, and M. pneumoniae has been isolated from the urogenital tract in the absence of clinical signs.

The majority of studies on clinical aspects of M. pneumoniae mycoplasmosis address the diagnosis, treatment and prevention of CAP, while factors predisposing to extra-respiratory diseases remain virtually unexplored. Extracellular "spreading factors" like sialidase are wellknown virulence determinants of other pathogenic microorganisms, and are targets for chemotherapy in diseases such as influenza. Sialidase is associated with systemic dissemination during infection with many bacterial species, most notably Streptococcus pneumoniae and Clostridium perfringens, but such glycosidases were only recently documented to occur in certain species of Mycoplasma. The sialidase activity expressed by mycoplasmas can vary significantly among strains within a species, from undetectable to amounts that correlate positively with strain virulence. Very few isolates of
Ciomed Central

(c) 2011 Brown et al; licensee BioMed Central Ltd. This is an open access article distributed under the terms of the Creative Commons Attribution License (http://creativecommons.org/licenses/by/2.0), which permits unrestricted use, distribution, and reproduction in any medium, provided the original work is properly cited. 
Table 1 Diverse outcomes associated with Mycoplasma pneumoniae infection ${ }^{\text {a }}$

\begin{tabular}{|c|c|c|}
\hline Aural & $\underline{\text { Dermal }}$ & Musculoskeletal \\
\hline - otitis externa & - bullous exanthema & - reactive arthritis \\
\hline - otitis media & - cutaneous vasculitis & - rhabdomyolysis \\
\hline - myringitis & - erythema nodosum & - septic arthritis \\
\hline$\underline{\text { Cardiac }}$ & - Stevens-Johnson syndrome & $\underline{\text { Ocular }}$ \\
\hline - arrhythmia & - ulcerative stomatitis & - conjunctivitis \\
\hline - myocarditis & • urticaria & - iritis \\
\hline - pericardial effusion & - vesicular rash & - retinitis \\
\hline - pericarditis & Gastrointestinal & - uveitis \\
\hline Central nervous system & - hepatitis & Renal \\
\hline - ataxia & - pancreatitis & - glomerulonephritis \\
\hline - Bell's palsy & $\underline{\text { Hematologic }}$ & - IgA nephropathy \\
\hline - choreoathetosis & - aplastic anemia & - interstitial nephritis \\
\hline - encephalitis & - hemolytic anemia & $\underline{\text { Respiratory }}$ \\
\hline • encephalomyelitis & - hemophagocytosis & - primary atypical pneumonia \\
\hline - Guillain-Barre- syndrome & - intravascular coagulation & \\
\hline - meningoencephalitis & - lymphadenopathy & \\
\hline - meningitis & - neutropenia & \\
\hline - paralysis & - neutrophilia & \\
\hline - polyradiculitis & - septicemia & \\
\hline - psychosis & - thrombocytopenia & \\
\hline
\end{tabular}

M. pneumoniae have been examined for sialidase activity, so it was unknown whether sialidase may contribute either to PAP or to extra-respiratory diseases involving this species. To establish the baseline frequency of its occurrance in $M$. pneumoniae, we conducted a retrospective survey for sialidase activity in clinical isolates associated with respiratory mycoplasmosis.

\section{Methods}

Fifteen laboratory strains of M. pneumoniae, including the well-known virulent strain PI1428 (American Type Culture Collection accession number 29085, from a patient with PAP), SAD03, SAD05, TW11-4, 1RCH, 9RCH, 11-61, 104.2, 142-48, 256-8, 541-6, 541-29, 1161, 1311 and 15531, plus 91 clinical isolates from cases of radiologically-confirmed interstitial pneumonia were tested. The de-identified clinical isolates had been banked over a period of many years from patients diagnosed with CAP at various locations in the US. They were isolated from four distinct sites in the respiratory tract: 61 were from throat swabs, 4 from nasal swabs, 17 from sputum, and 9 from bronchoalveolar lavage fluid. The latter were considered by clinicians to be invasive because they were from patients hospitalized with severe pneumonia. It was unknown whether any of the patients had been diagnosed as having pneumonia attributable solely to $M$. pneumoniae, or had been treated empirically with viral neuraminidase inhibitors.
Frozen stocks of mycoplasma were passaged one time in SP-4 medium supplemented with $10 \% \mathrm{w} / \mathrm{v}$ glucose and $15 \% \mathrm{v} / \mathrm{v}$ fetal bovine serum at $37^{\circ} \mathrm{C}$ in ambient air. Sialidase activity of $M$. pneumoniae cells suspended in conditioned medium was assessed using the fluorogenic substrate 2'-(4-methylumbelliferyl)- $\alpha$-D- $N$-acetylneuraminic acid (MUAN) as previously described [15]. Briefly, $50 \mu \mathrm{l}$ of stationary phase cultures were added to $50 \mu \mathrm{l}$ of $0.35 \% \mathrm{w} / \mathrm{v}$ MUAN in $30 \mathrm{mM}$ sodium acetate buffer, $\mathrm{pH}$ 4.5. Following $60 \mathrm{~min}$ incubation at room temperature, fluorescence at $450 \mathrm{~nm}$ was quantitated using a spectrofluorometer (excitation at $350 \mathrm{~nm}$; cutoff filter at $420 \mathrm{~nm}$ ). The positive controls were Mycoplasma alligatoris strain $\mathrm{A} 21 \mathrm{JP2} 2^{\mathrm{T}}$, which expresses a cell-associated sialidase [16], and Type VI sialidase purified from Clostridium perfringens. The negative controls were Mycoplasma crocodyli strain MP145 ${ }^{\mathrm{T}}$, which does not express any sialidase, and fresh culture medium.

\section{Results}

No sialidase activity was detected in any specimen, thus there was no evidence that the enzyme contributes to PAP involving M. pneumoniae. However, the undocumented clinical significance of $M$. pneumoniae isolation from these patients is a recognized weakness of this study. It seems unlikely that potential empiric treatment with viral neuraminidase inhibitors strictly precluded isolation of sialidase-positive strains of $M$. pneumoniae 
from any of these patients, but this remains to be definitively established.

The ability of certain M. pneumoniae strains to cause extra-respiratory mycoplasmosis may require additional cellular functions, which can be genetically acquired in vivo from the polymicrobial community within the human host. The presence of bacterial spreading factors such as sialidase might explain the differences in clinical manifestations of infection with certain strains of $M$. pneumoniae. Sialidase is a prominent candidate for this because of its well-documented tendency to be horizontally transferred among bacteria [17]. In addition, quantitative variation of sialidase activity among strains of other pathogenic mycoplasmas ranges from undetectable to extremely high in significant correlation with strain invasiveness [18]. A possible involvement of sialidase in neurologic or other manifestations of invasive disease remains to be investigated, but a bank of those less common specimens will be required to determine whether PAP-associated strains are less likely to express sialidase activity than strains associated with other outcomes of M. pneumoniae mycoplasmosis. We conclude that the annotated genome of the well-known virulent strain M129 (GenBank accession number NC_000912), also isolated from a patient with pneumonia (American Type Culture Collection accession number 29342), accurately represents the absence of sialidase genes from strains of M. pneumoniae typically associated with uncomplicated PAP.

\section{Acknowledgements \\ The clinical isolates of M. pneumoniae were obtained from Dr. Ken B. Waites of the University of Alabama at Birmingham, Birmingham AL, USA, and handled in accordance with a protocol approved by the University of Florida's Institutional Review Board (UF IRB \# 89-2009). We thank Dina Demcovitz, Amy Ratliff and Lynn Duffy for technical assistance. This work was supported by Public Health Service grant 1R01GM076584 from the US National Institute of General Medical Sciences (DRB). Publication of this article was funded in part by the University of Florida Open-Access Publishing Fund. \\ Author details \\ 'Department of Biological Sciences, Towson University, Towson MD, USA. ${ }^{2}$ Department of Infectious Diseases and Pathology, College of Veterinary Medicine, University of Florida, Gainesville FL, USA.}

\section{Authors' contributions}

MM jointly conceived the study and participated in study design; collected analyzed and interpreted the data; and drafted the manuscript. DRB jointly conceived the study and participated in study design; reviewed the data analysis and interpretation; and revised the manuscript for important intellectual content. Both authors have read and approved the final version of the manuscript.

\section{Competing interests}

The authors declare that they have no competing interests.

\section{References}

1. Krause DC, Taylor-Robinson D: Mycoplasmas which infect humans. In Mycoplasmas: Molecular Biology and Pathogenesis. Edited by: Maniloff J. Washington, DC, American Society for Microbiology Press; 1992:417-444.

2. Waites $K$, Talkington D: New developments in human diseases due to mycoplasmas. In Mycoplasmas: Molecular Biology, Pathogenicity, and Strategies for Control. Edited by: Blanchard A, Browning GF. Norfolk, Horizon Bioscience; 2005:289-354

3. Atkinson TP, Balish MF, Waites KB: Epidemiology, clinical manifestations, pathogenesis and laboratory detection of Mycoplasma pneumoniae infections. FEMS Microbiol Rev 2008, 32:956-973.

4. Freeman R, McMahon M: Acute pancreatitis and serological evidence of infection with Mycoplasma pneumoniae. Gut 1978, 19:367-370.

5. Arav-Boger R, Assia A, Spirer Z, Bujanover Y, Reif S: Cholestatic hepatitis as a main manifestation of Mycoplasma pneumoniae infection. J Pediatr Gastroenterol Nutr 1995, 21:459-460.

6. Daxboeck F, Blacky A, Seidl R, Krause R, Assadian O: Diagnosis, treatment, and prognosis of Mycoplasma pneumoniae childhood encephalitis: systematic review of 58 cases. J Child Neurol 2004, 19:865-871.

7. al-Abassi A: Acute pancreatitis associated with Mycoplasma pneumoniae: a case report of missed diagnosis. Med Princ Pract 2002, 11:112-115.

8. Vic P, Blondin G, Blayo M, Finel E, Daaboul M, Queinnec C, Broussine L: Pancréatite aiguë et infection à Mycoplasma pneumoniae [Acute pancreatitis and Mycoplasma pneumoniae infection]. Arch Pediatr 2004 11:154.

9. Del Castillo M, D'Giano C, Goicoechea M, Morello F, Salsamendi P, Mora A: Mycoplasma pneumoniae meningoencephalitis in a young adult. Medicina (B Aires) 2005, 65:338-340.

10. Stamm B, Moschopulos M, Hungerbuehler H, Guarner J, Genrich G, Zaki S: Neuroinvasion by Mycoplasma pneumoniae in acute disseminated encephalomyelitis. Emerg Infect Dis 2008, 14:641-643.

11. Walter ND, Grant GB, Bandy U, Alexander NE, Winchell JM, Jordan HT, Sejvar JJ, Hicks LA, Gifford DR, Alexander NT, Thurman KA, Schwartz SB, Dennehy PH, Khetsuriani N, Fields BS, Dillon MT, Erdman DD, Whitney CG, Moore MR: Community outbreak of Mycoplasma pneumoniae infection: school-based cluster of neurologic disease associated with household transmission of respiratory illness. J Infect Dis 2008, 198:1365-1374.

12. Lee S, Yang S, Chang C, Yeh H, Chow W: Mycoplasma pneumoniaeassociated acute hepatitis in an adult patient without lung infection. $J$ Chin Med Assoc 2009, 72:204-206.

13. Narita M, Yamada S, Nakayama T, Sawada H, Nakajima M, Sageshima S: Two cases of lymphadenopathy with liver dysfunction due to Mycoplasma pneumoniae infection with mycoplasmal bacteraemia without pneumonia. J Infect 2001, 42:154-156.

14. Romero-Gómez M, Otero MA, Sánchez-Muñoz D, Ramírez-Arcos M, Larraona JL, Suárez García E, Vargas-Romero J: Acute hepatitis due to Mycoplasma pneumoniae infection without lung involvement in adult patients. J Hepatol 2006, 44:827-828.

15. May M, Brown DR: Secreted sialidase activity of canine mycoplasmas. Vet Microbiol 2009, 137:380-383.

16. Brown DR, Zacher LA, Farmerie WG: Spreading factors of Mycoplasma alligatoris, a flesh-eating mycoplasma. J Bacteriol 2004, 186:3922-3927.

17. Roggentin P, Schauer R, Hoyer L, Vimr E: The sialidase superfamily and its spread by horizontal gene transfer. Mol Microbiol 1993, 9:915-921.

18. May M, Kleven SH, Brown DR: Sialidase activity in Mycoplasma synoviae. Avian Dis 2007, 51:829-833.

doi:10.1186/1756-0500-4-195

Cite this article as: May and Brown: Retrospective survey for sialidase activity in Mycoplasma pneumoniae isolates from cases of communityacquired pneumonia. BMC Research Notes 2011 4:195. 